\title{
Bone health in epilepsy
}

\author{
Bindu Menon $^{\mathrm{a}, *}$, Man Mohan Mehndiratta ${ }^{\mathrm{b}}$ \\ a Department of Neurology, Apollo Speciality hospital Nellore, India \\ b Janakpuri Super Speciality Hospital, New Delhi, India
}

\section{A R T I C L E I N F O}

\section{Article history:}

Received 9 August 2016

Accepted 7 April 2017

Available online 20 April 2017

\section{Keywords:}

Antiepileptic drugs

Bone health

\section{A B S T R A C T}

Epilepsy is one of the most common neurological disorder usually requiring life long treatment. Long term treatment with antiepileptic drugs (AED's) is associated with chronic side effects which includes effect on bone health

There is a growing volume of literature suggesting that chronic use of AED in patients with epilepsy significantly reduces bone mineral density (BMD) with an increased fracture risk. The causes of these associations are likely to be multifactorial. Unlike other chronic side effects, symptoms of bone loss are insidious and asymptomatic; hence they are usually not recognized, and thus untreated. Hence one needs to determine the presence of osteoporosis before the overt signs are evident to reduce fracture risk. Evaluation of bone health is mandatory for a comprehensive treatment and to provide calcium and 25$\mathrm{OH}$ vitamin-D 3 supplementation if needed. The goals of epilepsy treatment are to achieve seizure freedom while minimizing adverse effects of treatment. Management goal should include a comprehensive care of the patient and this includes much more than controlling seizures.

(c) 2017 Indian Epilepsy Society. Published by Elsevier, a division of RELX India, Pvt. Ltd. All rights reserved.

\section{Contents}

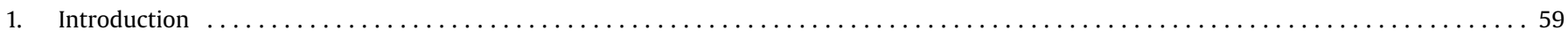

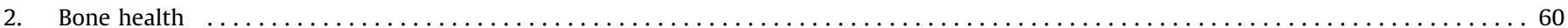

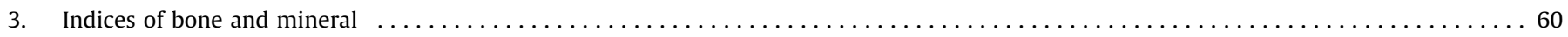

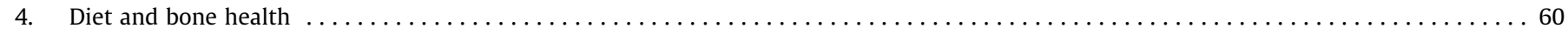

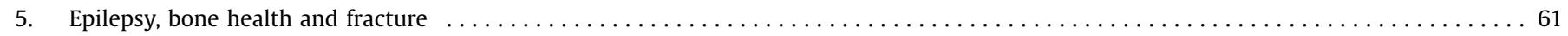

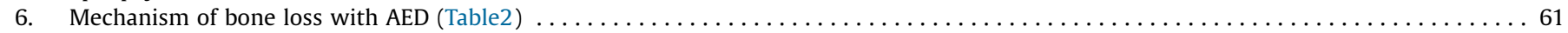

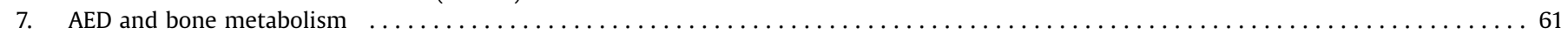

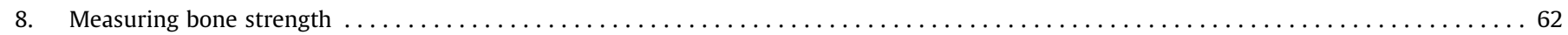

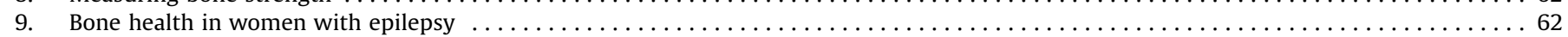

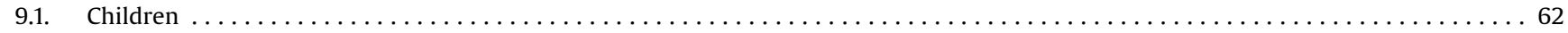

9.2. Recommendations for maintaining bone health in patients on AED's $\ldots \ldots \ldots \ldots$

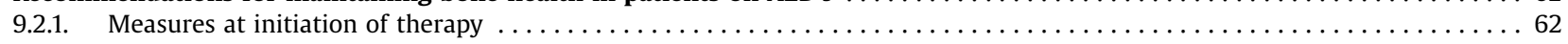

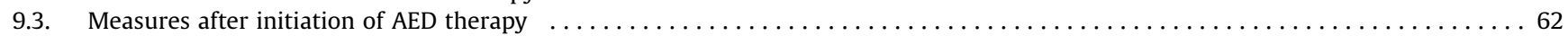

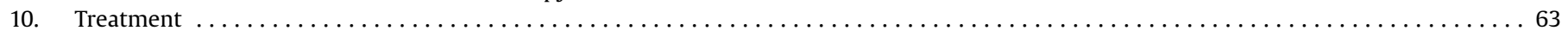

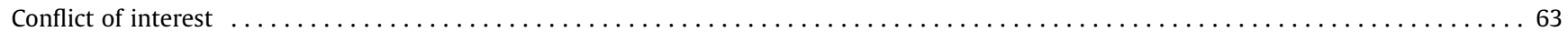

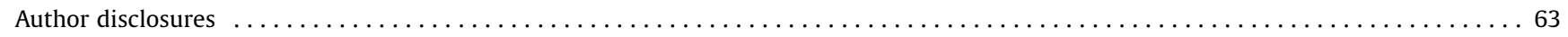

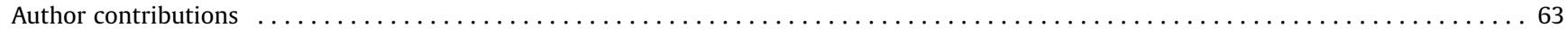

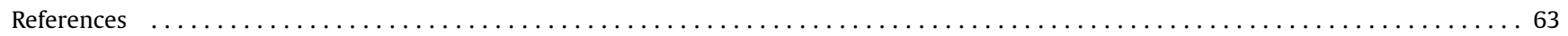
${ }^{*}$ Corresponding author at: Apollo Hospitals, Nellore, 524002 Andhra Pradesh,
India.

E-mail address: bneuro_5@rediffmail.com (B. Menon).

\section{Introduction}

There have been reports of AED induced osteomalacic biochemical abnormalities dating back to early 70's. ${ }^{1}$ Long term AED use in patients with epilepsy have been known to induce 
hypocalcemia, hypophosphatemia, increased levels of serum alkaline phosphatase, hyperparathyroidism, hypovitaminosis D, radiographic changes of rickets,

Chronic AED therapy in patients with epilepsy causes abnormalities in calcium metabolism, including hypocalcemia, hypophosphatemia, elevated levels of serum alkaline phosphatase and serum parathyroid hormone, reduced serum levels of biologically active vitamin D metabolites, radiologic evidence of rickets, and histologic evidence of osteomalacia. ${ }^{2-5}$ Earlier studies have shown that 20 to $65 \%$ of patients on AED predominantly institutionalized progressed to show evidence of rickets or osteomalacia. ${ }^{3,5-7}$ This results in fracture and reports of increased incidence of fracture are seen in patients receiving AED. There is growing evidence of literature, which shows AED induced side effects on bone health, which includes the newer AED's too.

\section{Bone health}

Bone is a dynamic active tissue, which is under constant reconstruction all through life. Bone cells include osteoblasts which builds bone, osteocytes maintains strength, and osteoclasts, which resorb bone. The balance between the types of cells determines the bone density. Osteoblasts deposit an organic matrix, which is followed by mineralization by calcium and phosphorus. This mineral phase of bone is called hydroxyapatite. The formation of hydroxyapatite is determined by the concentration of calcium and phosphorus in plasma and extracellular fluid. There is a critical limit for the concentrations of calcium and phosphorus ions below, which the mineralization of organic matrix does not occur. ${ }^{8}$ Vitamin D and calcium play an important role in disorders of bone metabolism and their deficiency leads to skeletal abnormalities, ranging from varying from osteopenia to osteomalacia. Hypovitaminosis D has been implicated as a major cause for bone loss in patients with epilepsy. Bone loss is dependent on various factors like increasing age, physical inactivity, comedication acting on the bone metabolism, hormonal changes in women and various genetic factors.

Nutrition plays a key role in the maintenance of bone health. Needless to say, the nutrient store in early childhood and adolescent determines the bone status in old age. ${ }^{9}$ A diet low in calcium leads to hypocalcemia, which triggers secondary hyperparathyroidism leading to osteoclast activity and calcium release from bone

Aging changes the calcium metabolism leading to reduced intestinal calcium absorption and formation but with increased bone resorption. The demand of calcium increases in women of childbearing age group, postmenopausal women and old age.

Keeping in mind the role of nutrition, proper counseling about dietary calcium needs to be emphasized in women in preconception period, during pregnancy and during lactation as this affects the health and nutrition of the offspring.

\section{Indices of bone and mineral}

AED affects calcium and phosphate concentration in the body affecting the bone metabolism. Reports of AED induced hypocalcemia have ranged between $3 \%$ and $30 \% .{ }^{1,2,10-12}$ Hypophosphatemia has also been reported with AED's. ${ }^{13,14}$ Maintenance of bone health requires vitamin $\mathrm{D}$. Vitamin $\mathrm{D}$ level is the most common index of Vitamin D status and hypovitaminosis $\mathrm{D}$ have been reported in both adults and children taking AEDs. ${ }^{1,12-18} 1,25[\mathrm{OH}]$ 2D, the most active metabolite of vitamin $D$ has been found to be low in adults taking AEDs. ${ }^{19}$ Parathyroid gland secretes parathyroid hormone (PTH) and is directly involved in the regulation of calcium. With hypocalcemia, PTH levels increase, which in turn increases bone breakdown or resorption. AED therapy has been reported to cause hyperparathyroidism. ${ }^{10,20}$ Markers of bone formation have been assessed in patients receiving AEDs, which include alkaline phosphatase, osteocalcin, and the C-terminal extension peptide of type I procollagen. The most commonly used marker for bone formation was usually alkaline phosphatase and increased levels have been noted in both children and adults on AEDs. ${ }^{12,14,21,22}$ However as serum total alkaline phosphatase is also derived from other sources like bone and liver, it loses its sensitivity and specificity as a marker for bone disease. Hence studies addressing levels of serum total alkaline phosphatase measured the isoenzymes of bone fraction. ${ }^{16,23}$ High levels of osteocalcin, or bone-gla protein, synthesized predominantly by osteoblasts is a small noncollagenous protein that is specific for bone tissue have been reported in patients on AED treatment. $^{21,24,25}$ Elevated levels of Procollagen type I molecules secreted by osteoblastic cells have been seen in patients taking AEDs. ${ }^{21,25}$ Markers of bone resorption in patients on AED such as cross-linked carboxy-terminal telopeptide of human type I and hydroxyproline in the urine are elevated. ${ }^{21,25}$ The markers have been found to be elevated even with normal vitamin D and PTH levels. $^{26}$

\section{Diet and bone health}

Calcium and vitamin D form the framework of the bone and skeletal system. Body produces Vitamin D, a fat-soluble vitamin after exposure to ultraviolet (UV-B) rays from the sun. Sunlight is the predominant source of vitamin D. The food sources of Vitamin D are salmon, mackerel, tuna fish, sardines, liver, beef, swiss cheese, fortified milk and cereals. Indian diet lacks these food supplements. Moreover the food is not fortified with vitamin D in India. The calcium requirement changes with different stages of bone growth i.e. during growth spurt, pregnancy and lactation, elderly. The dietary sources of calcium in the diet are milk and other dairy products, such as hard cheese, cottage cheese, yogurt, as well as green vegetables, like spinach. Hence calcium can be obtained through diet, vitamin D source remains sunlight exposure and fortified food. Fortification of milk is followed in most countries, however not followed in India. Recommended Dietary Allowances (RDA) of calcium of $600 \mathrm{mg}$ in adult men, women and $1000 \mathrm{mg}$ pregnant and lactating women as per the Indian Council of Medical Research (ICMR) guidelines. ${ }^{27}$ This is in contrast to 800 to $1000 \mathrm{mg}$ /day for adult men and women and 1200 to $1300 \mathrm{mg} /$ day for pregnant and lactating mothers by United States. ${ }^{28}$ (Table 1). A study evaluating the dietary pattern in people with epilepsy (PWE) on AED with regard to calcium and related minerals concluded that the dietary consumption of calcium of all the patients was far below the recommended daily dietary allowance (RDA). ${ }^{29}$ Bone is a dynamic active tissue, which is under constant reconstruction all through life. Low calcium in diet causes hypocalcemia, which in turn triggers secondary

Table 1

Recommended Dietary Allowances of calcium in India and USA.

\begin{tabular}{lll}
\hline Category & India (27) & India (27) \\
\hline Units & $\mathrm{mg} /$ day & $\mathrm{mg} / \mathrm{day}$ \\
Infants & 500 & 500 \\
Infants 0-6 months. & 500 & 750 \\
Infants 6-12 months. & & \\
Children Boys E Girls & 400 & 800 \\
1-9 years. & 500 & $1200-1300$ \\
10-15 years. & 500 & $1200-1300$ \\
16-18 years. & 400 & $800-1000$ \\
Men & 400 & $800-1000$ \\
Women & 1000 & $1200-1300$ \\
Pregnant E Lactating Mothers & & \\
\hline
\end{tabular}


hyperparathyroidism, which causes increased osteoclast activity, and finally calcium releases from bone making bone weak.

\section{Epilepsy, bone health and fracture}

The association of epilepsy and increased risk of fractures have been noted. Factors related to this increased fracture risk include falls during a seizure or drowsiness and incoordination due to AED effect or part of symptomatic epilepsy. ${ }^{30,31}$ Low BMD associated with epilepsy and AED may also play a contributory role. ${ }^{31,32}$ Antiepileptic drug (AED) treatment has adverse effects on bone and mineral metabolism increasing the fracture risk. ${ }^{33}$ Patients with epilepsy have two to six times more frequency of fractures than general population. ${ }^{33-35}$ Patients older than 40 years, taking enzyme inducing AED's for 2 years have significantly lower BMD at strategic areas of fracture risk sites. ${ }^{36}$ Moreover, unexpected pathological fractures occurring during normal activity are also increased. ${ }^{31}$ Pathologic and traumatic fractures may be due to the underlying AED induced osteopenia or osteoporosis. ${ }^{37}$ Long term AED treatment with enzyme-inducing drugs (EIAED) induces vitamin $\mathrm{D}$ metabolism reducing $\mathrm{BMD}$, however, non enzyme inducing AED (NEIAED), valproate (VPA), has also been reported to reduce bone density. ${ }^{19}$ Pathologic fractures occur in 20 to $40 \%$ of patients on AED who are generally in low risk group for developing fractures. ${ }^{31}$ AED use increases the risk of fracture by 2 - to 4 -fold at clavicle spine or ankles with $69 \%$ of the reported fractures being not related to seizures. ${ }^{38}$ High risk factors are chronic AED use and elderly women with increased rates of bone loss at the calcaneus and hip. The risk of hip fracture increases by $29 \%$ over 5 years among women age 65 years and older. ${ }^{39}$ A cohort study evaluating the risk of fracture in patients with active epilepsy from 1993 to 2008 concluded that EIAED might increase the risk of fracture in patients with epilepsy. The result showed that for every 10,000 women treated with NEIAEDs for one year; there could be 48 additional fractures, including 10 additional hip fractures. For every 10,000 men treated with EIAEDs for one year, there could be 4 additional hip fractures. ${ }^{40}$

A meta-analysis of twenty-two studies to evaluating the link between use of AEDs and fracture risk, both though both EIAED's and NEIAEDs were associated with increased fracture risk, it was more for enzyme-inducing AED's ( $R R=1.18$; 95\% CI 1.11-1.25). Considering individual AED's phenobarbiturate (PB), topiramate (TPM) and phenytoin (PHT) suggested an increase in fracture risk of $78 \%, 39 \%$ and $70 \%$, respectively. ${ }^{41}$

\section{Mechanism of bone loss with AED (Table 2)}

There are several mechanisms for the AED drug induced reduction in bone density. ${ }^{42}$ (42) AEDs such as carbamazepine (CBZ), phenobarbital, and phenytoin accelerate hepatic microsomal metabolism of vitamin D to polar metabolites other than (25$\mathrm{OH}$ ) vitamin $\mathrm{D}$ (25-OHD) and increase the metabolism of 25-OHD into biologically inactive products. ${ }^{43}$ AEDs such as phenytoin (PHT), carbamazepine (CBZ), primidone (PRM), and phenobarbital (PB) are inducers of the cytochrome P450 enzyme system and are most commonly associated with altered bone metabolism and decreased bone density. ${ }^{21,44,45}$

AEDs may interfere with intestinal absorption of calcium causing hypocalcemia, which leads to hyperparathyroidism due to negative feedback. Experimental studies in rats showed markedly decreased calcium absorption with PHT but not with PB. ${ }^{46}$ Animal studies have shown that there may be inhibition of the cellular response to PTH. Hypocalcemia has been frequently seen due to inhibition of the bone resorptive response to PTH. Hyperparathyroidism is another suggested possible mechanism. This can be associated with normal vitamin D status ${ }^{21}$ or hypovitaminosis. ${ }^{20}$ Hyperparathyroidism activates bone resorption as a primary phenomenon and secondarily activate bone formation through a coupling phenomenon.

Two mechanisms are proposed for vitamin $\mathrm{D}$ inactivation by AEDs - hepatic enzyme induction and pregnane X receptor (PXR) and SXR activation. ${ }^{21,47,48}$ Vitamin D (D2 and D3) are normally taken up by the liver and transformed into $25(\mathrm{OH}) \mathrm{D}$ by the mitochondrial vitamin D hydroxylase CYP27A. The AED binds to the SXR and activates it. The complex binds to RXR, which then interacts with the vitamin $\mathrm{D}$ responsive element for the 24OHase. ${ }^{21,48,49,50}$ This accelerates the destructive process of $25(\mathrm{OH})$ $\mathrm{D}$ and $1,25(\mathrm{OH}) 2 \mathrm{D}$. This accelerated clearance will enhance the routine physiological adaptive mechanisms in response to progressive hypovitaminosis leading to secondary hyperparathyroidism.

Hypovitaminosis D also causes decreased calcium absorption in the intestine. VPA is a non-enzyme inducing AED and the reason for decreased BMD with VPA treatment is not well known. ${ }^{19}$ Both the EIAED and the NEIAED directly affects osteoblast and osteoclast activity maintaining a balance between them. ${ }^{19}$ Valprote association with BMD is probably by hormonal changes as suggested by the development of a polycystic ovary syndrome. EIAEDs apart from decreased calcium absorption also induce increased catabolism of sex steroids osteoporosis. ${ }^{32}$ Furthermore, A direct toxic effect of phenytoin on bone cells have been reported. ${ }^{51}$ Calcitonin deficiency is another postulated mechanism. Calcitonin is a hormone produced by the thyroid gland that inhibits osteoclastmediated bone resorption. Calcitonin deficiency has been demonstrated both in vitro and in vivo may therefore accelerate bone turnover. $^{52,53}$

\section{AED and bone metabolism}

Phenytoin affects bone metabolism by increasing vitamin $\mathrm{D}$ metabolism or directly inhibiting intestinal calcium absorption. 1,20 A study suggested that patients on phenytoin treatment may develop reduced BMD bone within 1 year. ${ }^{54}$ The effect of VPA on bone health is controversial. Initial reports did not find any significant abnormality on the effect of VPA on BMD. ${ }^{12,55}$ But later studies have found that adults taking long-term VPA have increased serum concentrations of calcium, low serum 1,25 $[\mathrm{OH}]_{2} \mathrm{D}$ concentration, and increased markers of bone resorption and formation. ${ }^{19}$ A metaanalysis of 11 studies which included 645 subjects evaluating effects of AED on lumbar spine found VPA found significantly decrease BMD of lumbar spine in epileptic children, while carbamazepine had no significant effect ${ }^{56,57}$ The effect of the newer AED on bone mineral metabolism and BMD has been studied in few studies. A study in adult patients on lamotrigine (LTG), topiramate, vigabatrin, gabapentin did not find any significant abnormality on bone mineral metabolism and BMD. $^{58}$ Children treated with VPA and LTG especially in combination developed short stature, low bone mass, and reduced bone formation. ${ }^{59}$ Polypharmacy further increases the risk of inducing low bone mass in adult patients. ${ }^{35}$ A study measuring BMD on children with epilepsy showed that lamotrigine might not interfere with bone accrual. ${ }^{60}$ A study done to access the rate of hip bone loss in older community dwelling men concluded that NEIAED was an independent predictor of increased rates of hip bone loss. ${ }^{61}$ A prospective study from south India showed that patients on AED with normal 25(OH) D levels at recruitment, irrespective of the type of antiepileptic medications even at subtherapeutic serum levels of the drug, developed 25(OH) D deficiency and insufficiency states at one year. ${ }^{62}$ NEIAED's can also affect bone health. A study comparing effect of levetiracetam and older AEDs on bone health concluded that both groups were 
Table 2

Suggested mechanisms for AED induced bone disease.

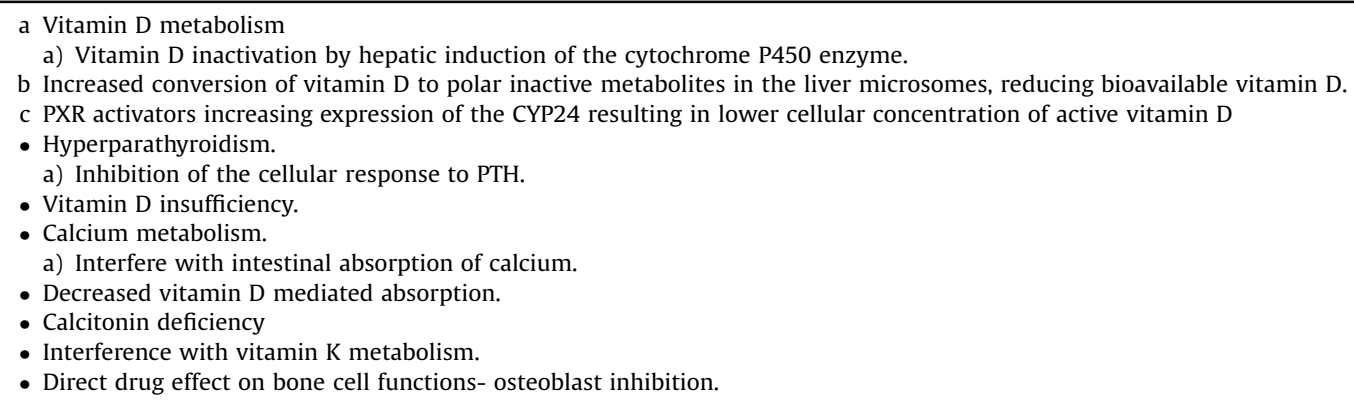

associated with reduced bone turnover and bone loss at fracture risk sites over 1 year. ${ }^{63}$

Yet another study analyzing effect of levetiracetam therapy on bone mineral density showed adverse effects on BMD though not significant and also noted a differential effect of AED between genders. ${ }^{64} \mathrm{~A}$ meta-analysis done to characterize bone health in children receiving AED's concluded that hypovitaminosis with

reduced bone density and impaired bone growth may be seen in children. However the study was cross sectional, included CBZ and VPA as primary study drugs and differed in skeletal sites. The study also concluded that Polytherapy was associated with a larger decrease in bone density than monotherapy. ${ }^{65}$

\section{Measuring bone strength}

Screening for bone health with direct measures can be done by direct measurement of bone densitometry by dual-energy x-ray absorptiometry (DEXA). The procedure is performed like a digital X ray. Bone density measurement is done at wrist, hip, and lower spine and then it is scored. If the score is less than -1.0 , the term "osteopenia" is applied. For a score less than -2.5 , it is called "osteoporosis." Adult patients receiving AEDs have shown significantly reduced BMD by using DEXA at the ribs and spine, ${ }^{37}$ femoral neck; $; 7,38,57$ and total hip. ${ }^{37}$ DEXA of the hip helps in identifying patients on AED's at risk for fractures. DEXA will be useful in situations where vitamin $D$ is normal which was seen in a study where young male patients on chronic AED had significant bone loss at the hip in the absence of vitamin D deficiency. ${ }^{38} \mathrm{~A}$ study showed that BMD for both the T- and Z-score of the lumbar spine, femur head, femoral neck and trochanter was significantly decreased in adults treated with AED and 59\% had osteopenia at either the spine or the hip. ${ }^{37}$

Both males and females with epilepsy on AED can have reduced BMD. Determining factors for the gender differences are age of onset of epilepsy, growth trends, and hormonal differences. Lower bone accrual in adolescence may contribute to increased fracture risk for both genders with epilepsy. ${ }^{66}$

\section{Bone health in women with epilepsy}

Epilepsy in women plays a different role as concerned to bone health. Several factors modulate the disease like sex hormones, menopause, which have gender specific implications on bone health. AEDs place women with epilepsy at increased risk for bone disorders and fractures, which is particularly for menopausal women.

In a study done on premenopausal women, phenytoin was seen to cause significant bone loss at femur over 1 year. However the study did not show any major adverse effects on bone turnover or bone mineral density with carbamazepine, lamotrigine and VPA. ${ }^{54}$ Women over 65 years on AED for more than 5 years are at risk of hip fracture by $29 \%$. Continuous AED use in elderly women is associated with increased rates of bone loss at the calcaneus and hip. ${ }^{39}$ A recent study showed that levetiracetam therapy for one year affected the lumbar spine BMD in females than males however the study had small size. ${ }^{64}$

\subsection{Children}

Chronic AED use in children also has shown to produce low bone mineral density and an increased risk of fracture. A study on 73 ambulatory children on VPA and oxcarbazapine showed significant decrease in growth velocity after 1 year of treatment. ${ }^{67}$ However a previous study with a follow up of 2 years did not find any bone loss in children receiving long-term AED medication. ${ }^{68}$

A study from a tropical country found that long term AED use puts children with epilepsy at risk for vitamin D deficiency. ${ }^{69} \mathrm{~A}$ recent analysis of 11 studies also concluded that reduced bone density, impaired bone growth, and vitamin $\mathrm{D}$ deficiency may be seen in children on AED. ${ }^{65}$

\subsection{Recommendations for maintaining bone health in patients on} AED's

\subsubsection{Measures at initiation of therapy}

1. Identify high-risk patients. (Postmenopausal, institutionalized, elderly, enzyme inducing AED, polytherapy)

2. Ensure patients undertake weight-bearing exercises to the comfort of the patient.

3. Maintain balanced diet with adequate calcium and sunlight exposure for vitamin $D$.

4. Advise to stop smoking, alcohol and avoid heavy caffeine drinks.

5. Prescribe $1000-1500 \mathrm{mg}$ of calcium and $400 \mathrm{IU}$ of vitamin D daily.

\subsection{Measures after initiation of AED therapy}

1. Measure calcium and 25- hydroxyvitamin D levels after 6-12 months of AED therapy

2. Yearly assessment of parameters if normal

3. If hypovitaminosis, initiate treatment after obtaining baseline BMD assessment by DEXA scan

4. Treatment includes vitamin D supplementation and biphosponates in consultation with endocrinologist. 


\section{Treatment}

There is insufficient data to prove the efficacy of prophylactic supplementation with calcium and vitamin D for patients at risk of reduced bone density from antiepileptic drugs. But studies have demonstrated that supplementation with vitamin D for ambulatory patients on AED increased bone density after 1 year of treatment. $^{70}$

There are several interventions available for bone disease, including calcium and vitamin D supplementation, bisphosphonates, hormone replacement, selective estrogen modulators (SERMs) and calcitonin, although few studies have addressed its efficacy in bone disease associated with AEDs. The two approved formulations of bisphosphonates include alendronate and risedronate. Bisphosphonates are potent inhibitors of bone resorption and with the information of AED associated increased bone resorption may be an effective treatment for bone disease in patients receiving AEDs. Role of hormone replacement in stopping bone loss is controversial. Moreover hormone replacement therapy may increase seizure activity. ${ }^{71}$

Bone health is an important long-term health concern for patients with epilepsy. There are certain recommendations for maintenance of optimal bone health in patients taking AED. As epilepsy requires long-term treatment, judicious choice and use of an AED is warranted while initiation keeping bone health in mind. ${ }^{72,73}$ PWE have an increased incidence of falls, injuries during seizures and fractures. Vitamin D deficiency may also lead to proximal weakness of muscles and falls. The presentation of epilepsy is diverse from mild to severe with some patients requiring institutionalization for their motor and mental handicap apart from their seizures. The role of regular exercise healthy diet, and nutritional supplementation cannot be overemphasized for maintenance of a healthy bone in persons with epilepsy.

\section{Conflict of interest}

The authors have none to declare.

\section{Author disclosures}

The authors report no disclosures relevant to the manuscript

\section{Author contributions}

Writing the manuscript: Prof Bindu Menon. Review and discussion of the manuscript: Bindu Menon, Man Mohan Mehndiratta. Critical revision of the manuscript for important intellectual content: Bindu Menon, Man Mohan Mehndiratta.

\section{References}

1. Hahn TJ, Hendin BA, Scharp CR. Effect of chronic anticonvulsant therapy on serum 25-hydroxycalciferol levels in adults. N Engl J Med. 1972;287:900-904.

2. Richens A, Rowe DFJ. Disturbance of calcium metabolism by anticonvulsant drugs. Br Med J. 1970;4:73-76.

3. Tolman KG, Jubiz W, Sannella JJ, et al. Osteomalacia associated with anticonvulsant drug therapy in mentally retarded children. Pediatrics. 1975;56:45-51.

4. Hahn TJ, Hendin BA, Scharp CR, Boisseau VC. Haddad JG: Serum 25hydroxycalciferol levels and bone mass in children on chronic anticonvulsant therapy. N Engl J Med. 1975;292:550-553.

5. Christiansen C, Rodbro P, Lund M. Incidence of anticonvulsant osteomalacia and effect of vitamin D: controlled therapeutic trial. BMJ. 1973;4:695-701.

6. Mosekilde L, Christensen SC, Lund B, Sorensen OH, Melsen F. The interrelationships between serum 25-hydroxycholcalciferol, serum parathyroid hormone and bone changes in anticonvulsant osteomalacia. Acto Endocrinol. 1977;84:559-565.
7. Sotaniemi EA, Hakkarainen HK, Puranen JA, Lahti RO. Radiologic bone changes and hypocalcemia with anticonvulsant therapy in epilepsy. Ann Intern Med. 1972;77:389-394.

8. Holick MF, Krane SM. Introduction to bone and mineral metabolism. In: Eugene B, Fauci A, Kasper D, Hauser S, Longo D, Jameson JL, eds. Harrison's Principles of Internal Medicine. In Harrison's Principles of Internal Medicine. 15th ed. New York: McGraw-Hill; 2001:2192-2194.

9. Garn SM. The Earlier Gain and the Later Loss of Cortical Bone: Nutritional Perspective. Springfield, IL: C.C Thomas; 1970.

10. Bouillon R, Reynaert J, Claes JH, Lissens W, De Moor P. The effect of anticonvulsant therapy on serum levels of 25-hydroxyvitamin D, calcium, and parathyroid hormone. J Clin Endocrinol Metab. 1975;41:1130-1135.

11. Berry JL, Mawer EB, Walker DA, Carr P, Adams PH. Effect of antiepileptic drug therapy and exposure to sunlight on vitamin D status in institutionalized patients. In: Oxley J, Janz J, Meinardi H, eds. Antiepileptic Therapy: Chronic Toxicity of Antiepileptic Drugs. Raven Press; 1983:185-192.

12. Gough H, Goggin T, Bissessar A, Baker M, Crowley M, Callaghan N. A comparative study of the relative influence of different anticonvulsant drugs, UV exposure and diet on vitamin D and calcium metabolism in outpatients with epilepsy. QJ Med. 1986;230:569-577.

13. Hoikka V, Callaghan N. Biochemical evidence for osteomalacia with carbamazepine therapy. Acta Neurol Scand. 1980;62:282-286.

14. Bogliun G, Beghi E, Crespi V, Delodovici L, d'Amico P. Anticonvulsant drugs and bone metabolism. Acta Neurol Scand. 1986;74:284-288.

15. Andress DL, Ozuna J, Tirschwell D, et al. Antiepileptic drug-induced bone loss in young male patients who have seizures. Arch Neurol. 2002;59:781-786.

16. Skillen AW, Peirides AM. Serum gamma glutamyl transferase and alkaline phosphatase activities in epileptics receiving anticonvulsant therapy. Clin Chim Acta. 1976;72:245-251

17. Stamp TCB, Round JM, Haddad JG. Plasma levels and therapeutic effect of 25hydroxycholecalciferol in epileptic patients taking anticonvulsant drugs. $\mathrm{Br}$ Med J. 1972;4:9-12.

18. Tjellesen L, Christiansen C. Serum vitamin D metabolites in epileptic patients treated with 2 different anticonvulsants. Acta Neurol Scand. 1982;66:335-341.

19. Sato Y Kondo I, Ishida S, et al. Decreased bone mass and increased bone turnover with valproate therapy in adults with epilepsy. Neurology. 2001;57:445-449.

20. Weinstein RS, Bryce GF, Sappington LJ, King DW, Gallagher BB. Decreased serum ionized calcium and normal vitamin D metabolite levels with anticonvulsant drug treatment. J Clin Endocrinol Metab. 1984;58:1003-1009.

21. Valimaki MJ, Tiihonen M, Laitinen K, et al. Bone mineral density measured by dual-energy X-ray absorptiometry and novel markers of bone formation and resorption in patients on anti-epileptic drugs. J Bone Miner Res. 1994;9:631637.

22. O'Hare JA, Duggan B, O'Driscoll D, Callaghan N. Biochemical evidence for osteomalacia with carbamazepine therapy. Acta Neurol Scand. 1980;62:282286.

23. Okesina AB, Donaldson D, Lascelles PT. Isoenzymes of alkaline phosphatase in epileptic patients receiving carbamazepine monotherapy. J Clin Pathol. 1991:44:480-482.

24. Takeshita N, Seino Y, Ishida $\mathrm{H}$, et al. Increased circulating levels of gammacarboxyglutamic acid-containing protein and decreased bone mass in children on anticonvulsant therapy. Calcif Tissue Int. 1989;44:80-85.

25. Verrotti A, Greco R, Latini G, Morgese G, Chiarelli F. Increased bone turnover in epileptic patients treated with carbamazepine. Ann Neurol. 2000;47:385-388.

26. Verrotti A, Greco R, Latini G, Morgese G, Chiarelli F. Increased bone turnover in prepubertal, pubertal, and postpubertal patients receiving carbamazepine. Epilepsia. 2002;43:1488-1492.

27. Recommended dietary allowances for macronutrients. Dietary Guidelines for Indians-A Manual. 2011: National Institute of Nutrition ICMR; 2017:89.

28. Committee to Review Dietary Reference Intakes for Vitamin D and Calcium, Food and Nutrition Board, Institute of Medicine. Dietary Reference Intakes for Calcium and Vitamin D. Washington, DC: National Academy Press; 2010.

29. Menon Bindu, Harinarayan Chittari Venkata, Raj Marella Neelima, Vemuri Swapna, Himabindu G, Afsana TK. Prevalence of low dietary calcium intake in patients with epilepsy: a study from South India. Neurol India. 2010;58:209212.

30. Koppel BS, Harden CL, Nikolov BG, Labar DR. An analysis of lifetime fractures in women with epilepsy. Acta Neurol Scand. 2005;111:225-228.

31. Sheth RD, Gidal BE, Hermann BP. Pathological fractures in epilepsy. Epilepsy Behav. 2006:9:601-605.

32. Vestergaard P, Tigaran S, Rejnmark L, Tigaran C, Dam M, Mosekilde L. Fracture risk is increased in epilepsy. Acta Neurol Scand. 1999;99:269-275.

33. Souverein PC, Webb DJ, Petri H, Weil J, Van Staa TP, Egberts T. Incidence of fractures among epilepsy patients: a population-based retrospective cohort study in the General Practice Research Database. Epilepsia. 2005;46:304-310.

34. Persson HB, Alberts KA, Farahmand BY, Tomson T. Risk of extremity fractures in adult outpatients with epilepsy. Epilepsia. 2002;43:768-772.

35. Appleton RE. Seizure-related injuries in children with newly diagnosed and untreated epilepsy. Epilepsia. 2002;43:764-767.

36. Petty SJ, Paton LM, O'Brien TJ, et al. Effect of antiepileptic medication on bone mineral measures. Neurology. 2005;65:1358-1365.

37. Farhat G, Yamout B, Mikati MA, Demirjian S, Sawaya R, El-Hajj Fuleihan G. Effect of antiepileptic drugs on bone density in ambulatory patients. Neurology. 2002;58:1348-1353. 
38. Pack AM. Falls and fractures in patients with epilepsy Is there an increased risk? If so, why?. Neurology. 2012;79:119-120.

39. Ensrud KE, Walczak TS, Blackwell T, Ensrud ER, Bowman PJ, Stone KL. Antiepileptic drug use increases rates of bone loss in older women: a prospective study. Neurology. 2004;62:2051-2057.

40. Nicholas JM, Ridsdale L, Richardson MP, Grieve AP, Gulliford MC. Fracture risk with use of liver enzyme inducing antiepileptic drugs in people with active epilepsy: cohort study using the general practice research database. Seizure. 2013;22:37-42.

41. Shen Chunhong, Chen Feng, Zhang Yinxi, Guo Yi, Ding Meiping. Association between use of antiepileptic drugs and fracture risk: a systematic review and meta-analysis. Bone. 2014;64:246-253.

42. Fitzpatrick LA. Pathophysiology of bone loss in patients receiving anticonvulsant therapy. Epilepsy Behav. 2004;5(2):S3-15.

43. Hamersvelt HW. Brains and bones. Nephrol Dial Transplant. 1998;13:801-802.

44. Sheth RD, Wesolowski CA, Jacob JC, et al. Effect of carbamazapine and valproate on bone mineral density. J Pediatr. 1995;127:256-262.

45. Chung S, Ahn C. Effects of anti-epileptic drug therapy on bone mineral density in ambulatory epileptic children. Brain Dev. 1994;16:382-385.

46. Koch HV, Kratf D, von Herrath D. Influence of diphenylhydantoin and phenobarbital on intestinal calcium transport in the rat. Epilepsia. 1972;13:829-841.

47. Zhou C, Assem M, Tay JC, et al. Steroid and xenobiotic receptor and vitamin D receptor crosstalk mediates CYP24 expression and drug-induced osteomalacia. J Clin Invest. 2006;116:1703-1712.

48. Tomita S, Ohnishi JI, Nakano M, Ichikawa Y. The effect of anticonvulsant drugs on vitamin D3-activating cytochrome P-450-linked monooxygenase system. J Steroid Biochem Mol Biol. 1991;39:479-485.

49. Theodoropoulos C, Demers C, Mirshahi A, Gascon-Barre M. 1,25-dihydroxy D3 down regulates the rat intestinal vitamin D3-25 hydroxylase CYP27A. Am J Physiol. 2001;281:E315-25.

50. Holick MF. Stay tuned to PXR: an orphan actor that may not be D-structive only to bone. J Clin Invest. 2005;115:32-34.

51. Takahashi A, Onodera K, Shinoda H, Mayanagi H. Phenytoin and its metabolite, 5-(4-hydroxyphenyl)-5-phenylhydantoin, show bone resorption in cultured neonatal mouse calvaria. Jpn J Pharmacol. 2000;82:82-84.

52. Vernillo AT, Rifkin BR, Hauschka PV. Phenytoin affects osteoblastic secretion from osteoblastic rat osteosarcoma 17/2.8 cells in culture. Bone. 1990;11:309312.

53. Kruse K, Suss A, Busse M, Schneider P. Monomeric serum calcitonin and bone turnover during anticonvulsant treatment and in congenital hypothyroidism.J Pediatr. 1987;111:57-63.

54. Pack AM, Morrell MJ, Randall A, McMahon DJ, Shane E. Bone health in young women with epilepsy after one year of antiepileptic drug monotherapy. Neurology. 2008;70:1586-1593.

55. Davie MW, Emberson CE, Lawson DE, et al. Low plasma 25-hydroxyvitamin D and serum calcium in institutionalized epileptic subjects: associated risk factors, consequences and response to treatment with vitamin D. QJ Med. 1983;205:79-91.
56. Kafali G, Erscelan T, Tanzer F. Effect of antiepileptic drugs on bone mineral density in children between ages 6 and 12 years. Clin Pediatr. 1999;38:93-98.

57. Sheth RD, Wesolowski CA, Jacob JC, et al. Effect of carbamazapine and valproate on bone mineral density. J Pediatr. 1995;127:256-262.

58. Stephen LJ, McLellan AR, Harrison JH, et al. Bone density and antiepileptic drugs: a case controlled study. Seizure. 1999;8:339-342.

59. Guo C, Ronen GM, Atkinson SA. Long-term valproate and lamotrigine treatment may be a marker for reduced growth and bone mass in children with epilepsy. Epilepsia. 2001;42:1141-1147.

60. Sheth RD, Hermann BP. Bone mineral density with lamotrigine monotherapy for epilepsy. Pediatr Neurol. 2007;37:250-254.

61. Ensrud KE, Walczak TS, Blackwell TL, Ensrud ER, Barrett-Connor E, Orwoll ES Osteoporotic Fractures in Men (MrOS) Study Research Group: antiepileptic drug use and rates of hip bone loss in older men: a prospective study. Neurology. 2008;71(10):723-730.

62. Menon B, Harinarayan CV. The effect of anti-epileptic drug therapy on serum 25-hydroxyvitamin D and parameters of calcium and bone metabolism-A longitudinal study. Seizure. 2010;19:153-158.

63. Hakami T, O'Brien TJ, Petty SJ, et al. Monotherapy with levetiracetam versus older AEDs: a randomized comparative trial of effects on bone health. Calcif Tissue Int. 2016;98:556-565.

64. Artemiadis AK, Lambrinoudaki I, Voskou P, Tsivgoulis G, Safouris A. Bougea A etal. Preliminary evidence for gender effects of levetiracetam monotherapy duration on bone health of patients with epilepsy. Epilepsy Behav. 2016;55:8486.

65. Vestergaard P. Effects of antiepileptic drugs on bone health and growth potential in children with epilepsy. Paediatr Drugs. 2015;17:141-150.

66. Sheth RD, Binkley N, Hermann BP. Gender differences in bone mineral density in epilepsy. Epilepsia. 2008;49:125-131.

67. Lin CM, Fan HC, Chao TY, et al. Potential effects of valproate and oxcarbazepine on growth velocity and bonemetabolism in epileptic children- a medical center experience. BMC Pediatr. 2016;3:61.

68. Serin HM, Koç ZP, Temelli B, Esen I. The bone mineral content alterations in pediatric patients medicated with levetiracetam, valproic acid, and carbamazepine. Epilepsy Behav. 2015;51:221-224.

69. Fong CY, Kong AN, Poh BK, et al. Vitamin D deficiency and its risk factors in Malaysian children with epilepsy. Epilepsia. 2016;(July)10.1111/epi.13443 [Epubaheadofprint].

70. Mikati MA, Dib L, Yamout B, Sawaya R, Rahi AC, Fuleihan Gel H. Two randomized vitamin $\mathrm{D}$ trials in ambulatory patients on anticonvulsants: impact on bone. Neurology. 2006;67:2005-2014.

71. Harden CL, Pulver MC, Ravdin L, Javobs AR. The effect of menopause and perimenopause on the course of epilepsy. Epilepsia. 1999;40:1402-1407.

72. Dilip Gude. Epilepsy, anti-epileptic drugs and bone health in children.J Pediatr Neurosci. 2011;6:93.

73. Vinayan KP, Nisha B. Epilepsy, antiepileptic drugs and bone health. Ann Indian Acad Neurol. 2006;9:90-97. 